\title{
RECONSIDERANDO A GREGORY BATESON: ACERCA DE LA PROPENSIÓN \\ A APRENDER
}

Revisiting Gregory Bateson: on propension to learn

Reconsideração Bateson: o propensão para aprender

\section{Roberto C. Frenquelli}

Universidad Nacional del Rosario. Facultad de Psicología. Fono: +54 341 4491339. Correo

electrónico: doctorfrenquellipalma@gmail.com

\section{Resumen}

Se trata de un trabajo que reconsidera la obra de Gregory Bateson en torno al tema de la propensión a aprender y la educación infantil. Pasa una rápida reseña sobre algunos conceptos básicos del pensador estudiado como relación, contexto, significado, explicación, tautología, diferencia y otros. Fundamentalmente intenta no descuidar el estilo batesoniano buscando afirmar sus ideas acerca del proceso de conocer, siempre orientado al cambio que supone aprender.

Concluye que el término propensión es posiblemente prescindible toda vez que implicaría cierto cierre repetitivo sin demasiado valor. Sostiene la noción de aprendizaje como transformación superior en la extensión de los procesos espirituales que pueblan la naturaleza.

Palabras clave: propensión, aprendizaje, educación, niño.

\begin{abstract}
This is a paper that reconsiders Gregory Bateson's work on the issue of propensity to learn and child education. Spend a quick review of some basic concepts of the thinker studied as relationship, context, meaning, explanation, tautology, difference and others. Fundamentally try not neglect the batesonian style looking assert their ideas about the process of knowing, always oriented change that involves learning.

It concludes that the term propensity is probably dispensable since they involve some repetitive closing without much value. He supports the notion of higher learning as transformation in the extension of spiritual processes that involves nature.
\end{abstract}


Key words: propensity, learning, education, child.

\section{Resumo}

Este é um trabalho que reconsidere a obra de Gregory Bateson sobre a questão da propensão para aprender e educação infantil . Passe uma rápida revisão de alguns conceitos básicos do pensador estudada como um relacionamento, contexto, significado , explicação, tautologia , diferença e outros. Fundamentalmente tentar não negligenciar o batesoniana estilo procurando fazer valer as suas ideias sobre o processo de conhecimento, a mudança sempre orientada que envolve aprendizagem.

Conclui-se que o termo propensão é provavelmente dispensável uma vez que envolvem fechar alguns repetitivo, sem muito valor. Ele suporta a noção de ensino superior como transformação na extensão de processos espirituais que povoam a natureza.

Palavras-chave: propensão, educação, aprendizagem, criança.

To see a world in a grain of sand and a heaven in a wild flower, hold infinity in the palm of your hand and eternity in an hour.

William Blake

\section{Como siempre, esto me recuerda una historia...}

Cuando recibí la invitación para participar en este monográfico sobre "Propensión a aprender y educación infantil" inmediatamente pensé en la obra de Gregory Bateson. Así fue como me comprometí con "Infancia, Educación y Aprendizaje”. De modo automático, casi inconciente, me pareció justo volver a un autor que me acompaña tanto durante tanto tiempo.

He estado unos cuantos meses empeñado. Leyendo y volviendo a leer por aquí y por allá. Pensando entretenidamente en momentos diversos, de esa manera tan cambiante y de alguna manera desprolija que me caracteriza. Ha sido una vuelta interesante, recorriendo otra vez a un autor que siempre he llevado a mi lado. Y como corresponde a todo aquello donde prima la pasión, también he experimentado cierto displacer. No tengo dudas que 
todo esto es de sesgo muy personal. Lo relato pues creo que me pone en buena sintonía con lo que pretendo tratar aquí.

La obra de Bateson no es muy extensa. Se puede resumir a un conjunto de dos o tres libros, tal vez alguno más; uno de ellos una serie de conferencias agrupadas de manera más o menos prolija, otros en colaboración. No parece haber sido una persona demasiado preocupada por escribir, por publicar. Su rigurosidad intelectual y su brillantez para penetrar lo distinto parecen haberlo alejado de las apariencias y el afán por publicar. Lo que ha dejado ha sido muy trillado por interpretaciones tan desvaídas como desviadas. $\mathrm{Su}$ nombre ha sido tomado al asalto por los partidarios de la "sistémica" en una operación al estilo 'pars pro toto' que no merece. No es justo encasillarlo en cierta parroquia del saber, aunque tampoco es posible. Es corriente escuchar: "Ah..., Bateson..., el del doble vínculo". Expresión reduccionista salvaje que lo rescata de un cierto anonimato mientras lo niega casi por entero.

Escribe con una mezcla de ciencia y poesía. Salta de la firmeza que impone hablar de la Teoría de los Tipos Lógicos de Russell a la lírica de los versos de William Blake. Se mueve entre ellos con cierta elegancia. No descuida cierto aire orientalista, que parece profesar en forma más o menos evidente. Su inmersión en el tema de las paradojas lo hace virar hacia un cierto tono endiablado, calificativo que vislumbro no le disgustaría para nada. Bateson se acerca decididamente a lo sacro y a lo profano. Tampoco descuida la ironía que suele ir de la mano de cierto humor. Casi no hace falta decir que es difícil ingresar a sus ideas. No solamente porque hoy, a varios años de su arribo a nuestras costas, sigue siendo peculiar. Sino también por su misma postura epistemológica, que cuestiona desde donde deber ser: desde lo implícito, desde lo inconsciente de cada uno, como cristalización en un ida y vuelta desde lo social ${ }^{1}$.

Pensador de fronteras, sus inquietudes son diversas. Nos pone en el camino de intentar entender diferentes cuestiones, que van desde la antropología, las matemáticas, la informática y la cibernética a la vida de los delfines, los bosques y las playas, de las ratas

\footnotetext{
${ }^{1}$ El concepto batesoniano de "epistemología implícita” es de gran valor. Nuestra manera de pensar, de decidir, se encuentra fuertemente enraizada en nosotros, inconscientizada. La mayor parte de los profesores de epistemología no tienen en cuenta este detalle. Suelen ser brillantes ejecutores de ciertos ejercicios retóricos, vacíos de contenido a poco que se adviertan los efectos que producen sobre sus estudiantes. El pensamiento crítico auténtico pasa por revisar nuestras premisas inconscientes. Toda una gran tarea.
} 
hasta el Santo Padre y de los esquizofrénicos a las grandes colectividades humanas. En Bateson, mencionar la interdisciplina y la complejidad es casi superfluo. Su pluma lo dice de manera directa, de manera tan simple como compleja. No le hace falta aclararlo. Hecho que lo distancia mucho de los pensadores habituales que no tienen más remedio que aludir a sus modos de pensar y decidir por medio de la explícita reiteración de contraseñas semánticas.

Su epistemología brota en cada momento, siempre anclada al hecho, a lo empírico. Su escritura no es críptica, aunque sí difícil. No hay una prescripción formal, rígida. Esta debe aparecer de la lectura misma, de las propias conclusiones de cada uno. No hay un 'préstamo' del orden. Propende a que éste no se confunda con la pulcritud ritual.

Y llevado por las palabras, he dicho "Propende...". He tropezado con la temática que nos ocupa. ¿Cómo pensar la propensión a aprender? ¿Cómo dialogar con su obra, a modo de sus geniales metálogos, donde en la estructura misma de la conversación se trate el tema? ¿Cómo aproximarse lo más fielmente posible a su espíritu?

\section{Proceso, cambio, aprendizaje, inconsciente}

Dueño de toda una teoría del aprendizaje, a medida que uno se va sumergiendo en su producción, se advierte que el cambio deviene siempre de la mano de un cierto proceso subjetivo, inconsciente, antes que nada.

Proceso, cambio, aprendizaje, inconsciente. Hay una cierta identidad cruzada entre estas palabras. Aprender es una secuencia, hay ciertos empadronamientos rizomáticos, de sentidos diversos, con variancia de formas. El proceso espiritual es multidimensional, no lineal, sin centro ni subordinaciones jerárquicas.

Si bien Bateson no es un psicoanalista, su idea del funcionamiento inconsciente encuentra en sus observaciones acerca de las codificaciones analógicas icónica y digital ciertos puntos de interesante coincidencia con Freud. Lo analógico icónico, cercano a lo ostensivo, es muy anterior a lo digital, tanto en lo filogenético como en lo ontogenético. La posibilidad de adjudicar nombres a las cosas es propiedad de lo humano; a la que, si bien siempre recurrimos, tanto que solemos decir que 'lo que no se nombra casi no existe', resulta también un débil revestimiento de la cosa en sí, en su medio elemental, donde prevalece la emoción y la acción. Se precipitará comunicacionalmente un choque entre los 
procesos primario y secundario, entre la homogeneidad de lo indiviso donde no existe el no, tal como en los sueños, con lo discreto, inhomogéneo propio del mundo de la lógica y la conciencia.

La comunicación implica un nivel denotativo, otro metalingüístico donde se toma el discurso referido al lenguaje y finalmente el metacomunicativo donde el lenguaje se refiere a la relación entre los hablantes. Bateson tiene una vigorosa entrada en el problema del lenguaje. Sus ideas son de gran interés para el educador. Basta con pensar en la fantástica diversidad de fenómenos que se dan en el aula. Tanto que posiblemente el contenido semántico implicado en ellos no sea de tanto valor. Al menos en su nivel denotativo. Seguramente sí en lo metalingüístico, aún más en lo metacomunicativo ${ }^{2}$. Que buscan aclarar algo del significado inconsciente de lo que transcurre en la conversación educativa. Un terreno altamente paradojal que es imposible de soslayar.

\section{Pauta que conecta, diferencia, significado}

Desde sus primeros tiempos, ligado a la biología, después desde la antropología, mientras vive la explosión de la teoría de los conjuntos, los sistemas, la informática y la cibernética, piensa en un discurso integrado entre las ciencias naturales y las ciencias humanas. Asentado en aquello que Wiener resumiera como "ni masa ni energía, sino simplemente información", señala al pattern, traducido como "pauta" o "diferencia", como uno de los ladrillos fundamentales de su episteme. Habla de la "pauta que conecta". Conexión transindividual, que atraviesa desde lo inanimado a lo animado; la noción de información subtiende las estructuras, las "formas", buscando afanosamente dar sentido. Su noción de mente (mind), que ha sido también traducida al castellano como espíritu, necesariamente unida a la materia, es radicalmente distinta a las corrientes. Es una mente extensa, no confinada al sujeto individual. Es una mente que discurre en el seno de la biosfera. Los títulos de sus principales libros hablan por sí mismos: "Pasos hacia una ecología de la mente"; "Espíritu y naturaleza. Una unidad necesaria". La mente en Bateson es extensa, una suerte de psiquismo extenso. No es la mente limitada al psiquismo individual.

\footnotetext{
2 Lo metacomunicativo sostiene la comunicación sobre la comunicación. En ella es fundamental la retroalimentación constante, en ida y vuelta, entre emisor y receptor, aclarando el sentido de la conversación más en los aspectos implícitos que en los explícitos.
} 
Estas menciones no son meramente protocolares. Son verdaderos legados de este hombre, hijo de un afamado genetista, nacido en 1904 en Grandester (Reino Unido), fallecido en 1980 en San Francisco (USA). Este legado, antes que nada, es de un ejercicio de pensamiento, de una puesta en marcha de diferencias en pos de otro sentido. No es necesaria que esta diferencia sea extraordinaria, radicalmente nueva. Basta con que lo sea para quien lo advierte dentro de los límites de su self. Self que es siempre producto de la relación.

\section{Relación, conjunto, marco, contexto}

La relación entre componentes. Los componentes que logran el status de tales mediante la relación. La forma trasunta el fondo. Hay una identidad entre forma y fondo. Las formas se agrupan en conjuntos, dan los contextos. Ellos se leen siempre dentro de un marco. Es conocida la analogía del cuadro colgado de una pared: el marco separa el dibujo central del empapelado. Entre ambos se teje el significado. Los contextos se abren a otros contextos. Es clásico su diagrama que linealmente expresado transita desde el "contexto", al "contexto del contexto", al "contexto del contexto del contexto". Al que es preciso entrarle dándole una dentellada que hinque profundo en su medularidad, buscando salir de la mera enunciación. Como he dicho es difícil de entender, es menester leerlo mucho y, sobre todo, pasarlo por la dupla pensamiento - acción. Mejor si no se hace a solas.

Para Bateson todo es relación, marco y contexto. Su comprensión no podría pasar por otro medio. Por eso, también, resulta complicado escribir. Pues para escribir, sobre él o sobre cualquier otro punto, es menester el diálogo, llevado a sus límites, a un cierto más allá, en un metálogo ${ }^{3}$.

$\mathrm{Su}$ postura es nítidamente anti esencialista. Nadie es inteligente, depresivo o esquizofrénico por si mismo. Lo mismo que el carbono, el nitrógeno o el plomo. Todo vale en relación, un componente toma su valor junto a otro.

Todo se sostiene en lo que podríamos llamar la "lógica de lo viviente", la bio lógica. Por eso lo de los "marcadores" de contexto, indicios que prestan un marco orientador. Un contexto puede quedar como marco para otro contexto. Son anillos

\footnotetext{
${ }^{3}$ Un metálogo es una conversación donde no solamente se discute, sino que ella misma es pertinente al tema. El diálogo se tuerce sobre si mismo, la manera de conversar entra y sale del tema que se conversa.
} 
concéntricos, a modo de los encastres de las muñecas rusas. El paso de un "anillo contexto" a otro implica un salto cualitativo, otra configuración, una nueva diferencia. Donde se expresa el cambio y la creación. La diferencia genera otra diferencia. Nos ponemos a un paso de una semiosis expansiva. Esta expresión es casi perfecta a la hora de entender a nuestro autor.

\section{Descripción, explicación, tautología}

Toda descripción, como estas mismas líneas lo intentan, contiene un cierto nivel de explicación. Implican siempre un intento de conexiones entre proposiciones que siguen determinada formalidad. Nada más. Las proposiciones explicativas son casi meras “esgrimas verbales”, propias del ideal del lógico. Que no encierran gran criterio de verdad, menos de novedad. Es interesante reflexionar sobre su famoso aserto: "la ciencia no prueba, indaga". No hay experiencia objetiva. Para Bateson el desiderátum es la construcción compartida del sentido, eminentemente subjetiva.

Indagamos sobre tautologías ${ }^{4}$ con la esperanza de lograr un posible encuentro con lo azaroso, lo estocástico. El tiro del arquero, "su estocada", impactará sobre una cierta matriz prefigurada. Para Bateson lo nuevo asienta sobre lo redundante, casi como un efecto de sorpresa. El maestro ignora lo que su estudiante conocerá. Su único saber es que surgirá cierto saber en alguien que tampoco sabe lo que llegará a saber. Esta paradoja de lo viviente, la del que "sabe que no sabe", es un juego relacional donde lo implícito siempre es lo más poderoso. Casi no importa lo que se dice. Lo que importa es lo que se hace, sin negar las palabras claro, siempre en el talante de los afectos, de una cierta música, de cierta danza. La relación implica vínculo, comunicación, diálogo. Su pensamiento no es de la línea; es del círculo, tal vez mejor de la espiral ascendente. Lo nuevo siempre parte de lo aleatorio.

Asevera que el mundo no está hecho al ideal del lógico. ¡Felizmente! De otro modo la vida sería un aburrido intercambio de mensajes. Seguramente vanidosos, esperables, playos. El niño que busca el pezón apoyado en sus reflejos desde los primeros segundos de su vida extrauterina inicia una larga serie de aprendizajes donde la fisiología irá grabando

\footnotetext{
${ }^{4}$ Una tautología es un pensamiento expresado de diferentes maneras, aunque todas equivalentes. Repetición innecesaria, no aumenta la información. 
en las redes neurales la matriz intersubjetiva que le permitirá su condición de sujeto. Los reflejos, especie de subcomponentes de los instintos, dan paso a un proceso del aprender que va borrando la polaridad innata adquirida. El instinto, con sus mecanismos de reflejos encadenados, se torsiona, cambia. No es cierto que el instinto sea inmodificable. Por eso los animales juegan, logrando - al menos en ciertas especies - acceder a la paradoja. A aquello donde las cosas son y no son al mismo tiempo. Donde el niño es y no es. Pues es niño, pero siempre con otro. Por eso la mediación en la vida es una omnipresencia. No hay vida sin mediación. La lógica se quiebra cuando surge lo imprevisto. La canción de cuna es la cuna del acontecimiento. Una reiteración amorosa que espera lo distinto. Donde volverá a reinar la lógica sin saber que asienta en procesos que nada tienen que ver con ella. La mezcla de sus babas con la tierra que sus inquietas manitos han procurado, hace que el bebé logre plasmar sus primeras obras "rupestres". A las que saludará alborozado para después olvidar. Olvido que estará siempre al acecho de la oportunidad para volver en otras transformas. El olvido, visto de esta manera, es una forma de la memoria, reservorio del inconciente, reservorio de la acción. El enseñante es un despertador de olvidos. Eso sería mediar: estar en el medio de la historia y su reedición. Para ampliar la historia, en todas sus dimensiones. De los mares de la repetición se zarpa con la esperanza de llegar a la diferencia.

\section{Los aprendizajes como transformas}

El Aprendizaje 0 es aquel característico de las máquinas, independientemente de sus niveles de complicación. En este nivel no hay posibilidad de variación entre los elementos del conjunto, la oscilación está pautada por una secuencia definida en forma absoluta. Es totalmente previsible, sin posibilidad de lugar para el error. El error en este sistema no es tal. No hay error. Es simplemente una variante no prevista en la perfomance. Se asimila a las nociones más cerradas acerca de lo instintivo, a lo estereotipado e incapaz de aprovechar la experiencia. El conocimiento de estas organizaciones, que como se ha dicho, puede ser de alto valor, no puede expandirse desde sí mismo a una nueva pauta. Vale para su creación, para lo que podríamos llamar, su configuración. Y allí queda.

El Aprendizaje I supone una nueva elección dentro de los elementos fijos de un conjunto. Su ejemplo más común es el condicionamiento, tanto en su variante clásica como 
en la instrumental. Aparecen los marcadores de contexto, que pueden adquirir cierta relevancia generando actividad por sí mismos. Si su patrón se acerca al sitio donde se guarda la correa, nuestro cusquito comienza a mover la cola y se apresta a salir. El chiste batesoniano sobreviene cuando el humano cree a pies juntillas que el marcador de contexto es el correaje, mientras el perrito piensa exactamente lo mismo, pero al revés: "ahora vamos a salir y lo haré buscar mi correa moviendo mi colita...” El dueño es quien está, a su vez, ¡condicionado! Lo que se describe como condicionamiento pavloviano clásico es altamente intersubjetivo. Es lo que esperamos del otro, en la sonrisa, en el tacto, en la prosodia. Hay un intercambio bidireccional. Aquí hay ensayo y error. Nuestras vidas se mueven largamente entre estos dos aprendizajes.

El Aprendizaje II implica el pasaje de una experiencia contextual a otra. Es el del "contexto del contexto". Este cambio implica la chance de aprender a aprender, aprovechando la experiencia lograda. Su ejemplo más evidente puede ser el de la transferencia ${ }^{5}$, fenómeno universal descrito por el psicoanálisis: donde el imago materno, por ejemplo, es puesta en una persona diferente. A la que se le "proyectan" características similares, tratándosela en consecuencia. Nuestra pareja, heredera del imago materno, será y no será igual que nuestra madre. Todo un tema. Otro caso, más simple, puede ser el aprendizaje de idiomas o el desempeño alternativo en instituciones, viajes, etc. En el beneficio para la economía comportamental que puede desprenderse de este asunto nace otro problema. Es que, con este aprendizaje, también llamado deuteroaprendizaje, se va forjando una tendencia a la autovalidación. Es cuando la experiencia resulta un obstáculo. Puesto que la experiencia hace sentir su peso, ahora de resistencia a la transformación. Hay quien ha pensado a lo que solemos llamar experiencia como un hecho negativo sobre el que solemos recostarnos, contemplativos, orondos ${ }^{6}$. Es que el Aprendizaje puede ser, tranquilamente, un fenómeno negativo. No solamente en su valor por si mismo, también

\footnotetext{
${ }^{5}$ La noción psicoanalítica de transferencia es de una gran entidad, abarcando diferentes aspectos teóricos y técnicos de los que resulta imposible ahora ocuparnos. No obstante, vale la pena reflexionar sobre las múltiples transferencias que se dan, por ejemplo, en el aula, de los alumnos al docente y de éste a los alumnos. Lo mismo que entre los propios compañeros, entre los que suelen darse múltiples cruces. Fenómeno inconsciente, fogoneado por las experiencias primarias de cada uno, suele ser un poderoso factor a tener en cuenta en todo proceso educativo.

${ }^{6}$ Basarse extremadamente en lo que llamamos "experiencia" suele ser riesgosa manifestación de la estupidez humana. Los ejemplos sobran, en algunos casos de índole mortífera. El comando de guerra francés, tras la experiencia de la Gran Guerra no pudo ver que la nueva conflagración que advendría en Europa no sería de trincheras. Así se construyó la inútil línea Maginot, fácilmente sorteada por los invasores nazis.
} 
como cierre de otros caminos. Aprender el swing de tenis puede favorecer la incorporación del swing de golf. No obstante, ciertas habilidades pueden bloquear el desarrollo de otras parecidas. Aprender no siempre es un vergel poblado de florecitas rosadas.

El Aprendizaje III, siguiendo lo que ya podemos calificar como una escalera de tipos lógicos, implica una revisión del "contexto del contexto del contexto". Acarrea una reorganización profunda del carácter, algo muy raro de ver en el humano. Tal vez conectado en ciertas apariencias a la experiencia mística, tal vez a la locura, este cambio implica "patear el tablero" y volver a empezar. Algo por cierto complicado, tan inusual como peligroso. Uno puede morir en el intento, o ser encerrado en un manicomio ${ }^{7}$.

Tal vez valga la pena intentarlo. Pero muchos, no se sabe con qué grado de acierto, tratan de navegar lejos de sus corrientes. "Soldado de que huye, sirve para otra guerra" dice el viejo refrán. La huida como estilo de preservación puede ser aconsejable, aunque claro está, no nos acercará nunca a las posibles mieles de una diferencia intensa. Las psicoterapias, algo parecido y algo diferente a las instancias educativas, encuentran en este modo de aprendizaje un cenit al que se puede aspirar ${ }^{8}$.

Por fin, el Aprendizaje IV. Este es un punto poco desarrollado en la bibliografía batesoniana. Nos dice que es ajeno al hombre, en tanto no puede acceder al mismo. Lo vincula a un punto de reunión entre la Evolución y el Azar. Encuentro irrepetible, imprevisible. Es altamente compatible con su noción de mente que trasciende lo individual. Toca las sagradas nociones de una inteligencia superior antropocéntrica. De acuerdo a Bateson, "Dios es el ecosistema". Es un Dios que creo debería escribirse con minúscula. Pero él no lo hace, lo escribe con mayúsculas. Siempre he pensado en esta grafía. Entiendo que prefiere darle entidad a su Dios, desde luego no sobrenatural y sagrado. Es un dios laico. Que se puede tocar, del que uno forma parte, ínsitos en la naturaleza. Con la que lo humano se funde unitariamente. Es el sitio donde los ángeles no se atreven a pisar, tal como el nombre de su inconclusa obra póstuma, escrita junto a su hija Mary Catherine,

\footnotetext{
${ }^{7}$ Se supone que el revolucionario, a diferencia del delirante, suele tener la tener la habilidad social para que sus ideas novedosas logren ser compartidas, logrando ser entendido, evitando el rechazo.

${ }^{8}$ Las psicoterapias pueden pensarse como verdaderos reaprendizajes, buscando nuevos programas desde donde acercase a la vida. No son un hecho educativo, mucho menos instructivo. Pero la educación, sin dudas, es también una genuina oportunidad para la emergencia de lo distinto, para reprogramarse, dejando antiguas concepciones.
} 
"Angels fear". El Aprendizaje IV une filogenia con ontogenia. Sobre una matriz prefigurada ha incidido lo casual. En todo caso, el hombre en su versión "individual", se repartiría en la vastedad de las Ecologías: la medio ambiental, la social, la subjetiva. Una bella manera de configurar una ético estética sobre nuestro tema. Donde el aprender, con sus variaciones, desborda lo humano, adscribiéndose ni más ni menos que al orden de lo viviente en sentido amplio, evolutivo. El universo, lo creado, ha sido el producto inmanente de una larga marcha, donde el azar tuvo mucho que ver. Donde se expresa la forma superior de lo aprendido.

\section{7. ¿Y qué nos queda de la propensión?}

Si Bateson fuera preguntado sobre este concepto tal vez diría que es un componente del aprender, del niño mismo. Lo señalaría como un principio explicativo que, en realidad, como tal, no explica nada. A modo de un acuerdo convencional entre los científicos. "El niño aprende pues tiene propensión y es propenso pues aprende”, diríamos acercándonos un tanto a su tendencia al humor' .

"Todo escolar sabe" ... que propensión significa cierta tendencia o inclinación de cierto hecho observable. Así, por ejemplo, podemos hablar de la propensión de los jóvenes a llevar el pelo largo vistiendo jeans prolijamente rotos; lo mismo que si advertimos los cambios de la relación entre ciertas hormonas hipofisarias en torno a la ovulación o, si se quiere, de las colonias de hongos que crecen muy favorablemente sobre la cara de los árboles que miran hacia los vientos cargados de agua y frío. Todos los hechos, considerados en proceso, en su dinámica, muestran esta propiedad. Dicho con cierta simpleza, todo movimiento tiene su proclividad, su dirección.

Propensión a aprender podría reemplazarse, simplemente, por aprender. Y aprender por significar, volver a significar, significar, volver a significar. En términos de las ideas del autor que hoy revisamos, pautar creando diferencias que, a su vez, hacen diferencias. Movimientos antientrópicos, con aumento de la información, del tejido psíquico en su base

\footnotetext{
${ }^{9}$ Bateson llamó a este tipo de operaciones "principios dormitivos", tomando a Molière que imagina a ciertos doctos sabios que le preguntan a un candidato acerca de las razones por las cuales el opio hace dormir a una persona; el examinado contesta triunfalmente que el opio tiene un "principio dormitivo". Piensa de esta manera a ciertas hipótesis que suelen cerrar el pensamiento crítico, durmiéndolo.
} 
material. En proceso, donde todo va cambiando de forma, en movimientos inclusivos, que trascienden lo individual, siempre relacionales vinculares.

Podemos llamar a esto desarrollo, tal vez devenir. ¿Podemos, incluso, llamar a esto educación? Aun siendo bastante más arrojados, ¿podemos llamar a esto niño? Creo que sí. El niño no tiene necesariamente un "principio propensivo", cual especial energía que lo empuja al aprendizaje. El aprendizaje para Bateson es un proceso espiritual - mental, comunicacional, de orden y diferenciación, de puesta en forma. No es un proceso mecánico, de fuerzas.

En una economía de palabras, sin atrevimientos ni intenciones crípticas, creo que podemos hablar de lo viviente. De vida, a secas. La vida no sería otra cosa que la apertura a las transformaciones. En donde el hombre ha sido agraciado con la capacidad de protagonizar interesantes cambios, dentro de la inmensidad que lo incluye y desborda.

Termino aquí. He tratado de sumergirme en la red del espíritu batesoniano, buscando revisar su contexto y marco relacional, en diálogo. Tal vez con torpezas varias, con pocos aciertos. A sabiendas de las determinaciones inconscientes que siempre campean nuestros quehaceres he tratado de ser fiel a su estilo. Sin abandonar algunas ideas de mi propia cosecha, convencido de la amplitud del tema, de la inmensidad en la que estamos embarcados. Prefiero el error conceptual a la chatura de la copia. Tomo el riesgo. Ahora queda esperar lo que Usted, lector, quiera decir a partir de mis decires. Para que alguien pueda volver a empezar, recursivamente, "esto me recuerda una historia" ... Pues hay un parentesco entre historia y espíritu. Y con el aprender.

\section{Referencias bibliográficas}

Bateson, G. (1972). Pasos hacia una ecología de la mente. Una aproximación revolucionaria a la autocomprensión del hombre. Buenos Aires: Ediciones Carlos Lohlé.

Bateson, G. (1979 ). Espíritu y Naturaleza. Una unidad necesaria. Buenos Aires: Amorrortu editores.

Bateson, G. y Bateson, M.C. (1987). Angels fear. Towards an epistemology of the sacred. New York: Macmillan Publishing Company. 